\title{
Non-Hodgkin lymphoma and GIST: molecular pathways and clinical expressions
}

This article was published in the following Dove Press journal:

OncoTargets and Therapy

II December 2012

Number of times this article has been viewed

\author{
Michael Karanikas' \\ Nikolaos Machairiotis ${ }^{2}$ \\ Paul Zarogoulidis ${ }^{3,4}$ \\ Aikaterini Stylianaki ${ }^{3}$ \\ Nikolaos Corcoutsakis ${ }^{5}$ \\ Alexandros Mitrakas' \\ Panagiotis Touzopoulos' \\ Nikolaos Lyratzopoulos' \\ George Kouklakis ${ }^{6}$ \\ Manolis Spanoudakis ${ }^{7}$ \\ Alexandros Polychronidis' \\ 'Ist University Surgery Department, \\ ${ }^{2}$ Surgery Department, University \\ General Hospital of Alexandroupolis, \\ Alexandroupolis, Greece; ${ }^{3}$ Pulmonary \\ Department-Oncology Unit, \\ G. Papanikolaou General Hospital, \\ Aristotle University of Thessaloniki, \\ Thessaloniki, Greece; ${ }^{4}$ Pulmonary \\ Department-Interventional Unit, \\ Ruhrland Clinic, University of \\ Duisburg-Essen, Essen, Germany; \\ ${ }^{5}$ Radiology Department, ${ }^{6}$ Endoscopy \\ Unit, ${ }^{7}$ Hematology Department, \\ University General Hospital of \\ Alexandroupolis, Alexandroupolis, \\ Greece
}

Correspondence: Paul Zarogoulidis Pulmonary Department-Oncology Unit, G. Papanikolaou General Hospital,

Thessaloniki, Greece

Tel +30697 727 I974

$\mathrm{Fax}+302310992433$

Email pzarog@hotmail.com

\begin{abstract}
We report the case of a 64-year-old woman with a gastrointestinal stromal tumor and a diffuse large cell lymphoma. For this case, we conducted a literature review in an attempt to correlate these two neoplasms on a molecular basis. Diffuse large cell lymphoma is a subtype of non-Hodgkin lymphomas. The etiologic factor of these lymphomas is considered to be the mutations or allelic losses of the TP53 tumor suppressor gene and the overexpression of the bcl-2 oncogene. Gastrointestinal stromal tumors are mesenchymal tumors, which are typically defined by the expression of c-KIT (CD117) and CD34 genes in the tumor cells. Although there are references to dispersants in the literature about patients with both non-Hodgkin lymphoma and gastrointestinal stromal tumors, there is no common molecular pathway between these two diseases. In conclusion, there is no indication that these two neoplasms are relevant on a molecular basis.
\end{abstract}

Keywords: hematological malignacies, mesenchymal cells, gastrointestinal cancer

\section{Introduction}

A diffuse large-cell lymphoma (DLCL) of B-cell origin is a lymphoid neoplasm with diverse clinical manifestations. These neoplasms present as masses and grow rapidly, and cause symptoms when they infiltrate tissues or obstruct organs. These neoplasms can present either with B symptoms (fever, drenching night sweats, and weight loss) or pain when the lymphomatous mass enlarges rapidly. ${ }^{1}$ Gastrointestinal stromal tumors (GISTs) are relatively rare mesenchymal neoplasms of the gastrointestinal tract. GISTs develop from the Cajal cells and are the most common mesenchymal tumors of the gastrointestinal tract. They usually occur in the upper gastrointestinal tract, in areas such as the stomach; GISTs of the small bowel, esophagus, and rectum are less common. ${ }^{2}$ We report the case of a 64-year-old woman with a GIST and a DLCL. In this case, we conducted a literature review in an attempt to correlate these two neoplasms on a molecular basis.

\section{Case presentation}

A 64-year-old Caucasian female presented to the hospital with symptoms of infectious lung disease and weakness, with a medical history of rheumatoid arthritis, diabetes mellitus, and hypertension. She was accepted to the pulmonary department, where she was treated. During her treatment there, she was transfused with four units of packed red blood cells, and the computer tomography of her thorax revealed pathological lymph nodes of the mediastinum. Consequently, the patient was referred to the hematological department of our hospital with symptoms of fever starting 4 months before, drenching night sweats, weakness, and lung infection. She claimed a fever duration of 15 days, with three fever waves daily and 
a maximum body temperature of $40^{\circ} \mathrm{C}$, followed by 10 days without fever. The physical examination revealed bulky axillary lymph nodes, and a biopsy of the left cervical lymph node was taken. The biopsy was positive for DLCL, including mediastinum B-cell lymphoma. The immunohistochemistry was CD20+, PAX-5+, CD79 $\alpha+$, CD30+, MUM1+, OCT-2+, LMP-1+, p53+, BCL2++/-, cyclin D1--/+, CD45RA-, CD45-, CD45RO-, CD3-, CD5-, CD4-, CD8-, CD10-, BCL6-, AKL-1-, and EMA-. The patient's hematological check showed $32 \%$ hematocrit, 10.6 hemoglobin, 90 mean corpuscular volume, and 29 mean corpuscular hemoglobin after transfusion. Anisocytosis and hypochromia were also found, as well as rouleaux formation. The blood count revealed 6800 white blood cells and 200,000 platelets. The biochemical analysis showed elevated uric acid, aspartate transaminase, and alanine transaminase levels. Her beta-2 microglobulin was $8.00 \mathrm{mg} / \mathrm{L}$. Afterwards, a whole-body Gallium 67 scan and a computed tomography (CT) scan of her upper abdomen, lower abdomen, and retroperitoneal area were performed in order to define the stage of the disease. The stage was determined to be $\mathrm{II}_{\mathrm{B}}$, and the patient was started on a chemotherapy regiment of cyclophosphamide, hydroxydaunorubicin, vincristin, prednisolone, and rituximab. Nine circles of rituximab followed. After the ninth circle of chemotherapy, the patient was urged to have a thorax, upper abdomen, lower abdomen, and retroperitoneal area CT as part of her follow-up treatment.

The CT scan revealed a well-demarcated spherical mass that arose from the muscularis propria layer of the stomach in the level of the pylori, with overlying mucosal ulceration (Figure 1). The radiological image was compatible with that of a GIST, and the patient was accepted to the surgical department of our hospital. The patient complained of abdominal pain and discomfort, as well as belching. She was submitted for an esophagogastroduodenoscopy (EGD) and endoscopic ultrasonography. The EGD showed a polypoid mass with a $3-\mathrm{cm}$ diameter, with ulceration on the mass located in the pyloric antrum, findings indicating a possible GIST (Figure 2). A tumor resection was decided upon and the patient was submitted for subtotal gastrectomy with Billroth II reattachment. The surgical specimen (Figure 3) was sent for histological examination. The histological examination confirmed the GIST diagnosis and the immunohistochemistry showed that the tumor was CD117+, CD34+, and focally positive for NSE and GFAP antigens. Additionally, it was negative for the $\alpha$-SMA, myosin, desmin, S-100, CD3, and CD20 antigens. The tumor was fully resected and the lymph nodes were not infiltrated.

The 6-month follow-up included a thorax, upper abdomen, lower abdomen, and retroperitoneum area CT scan, as well

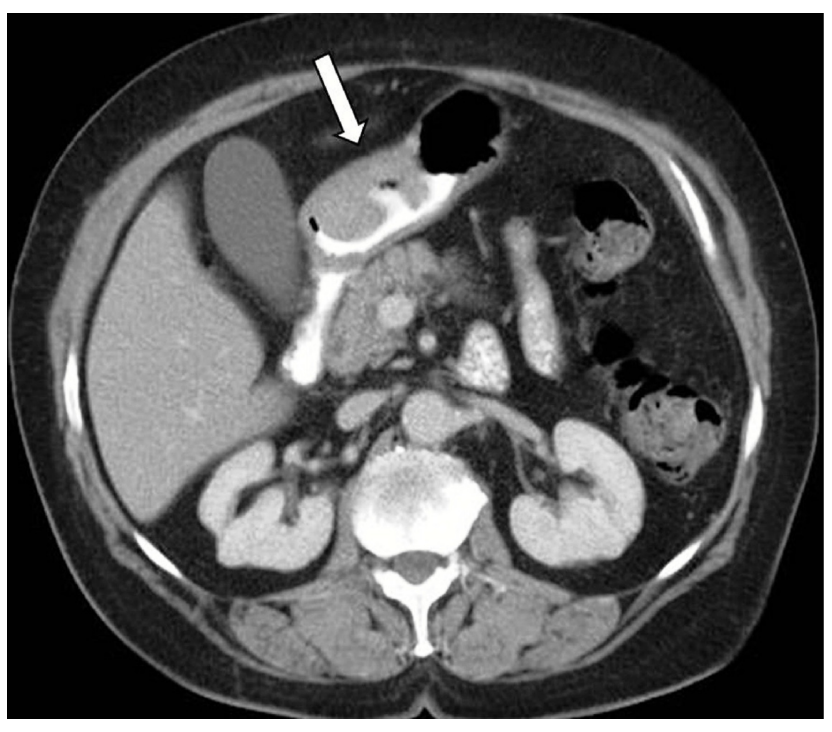

Figure I Computed tomography of the upper abdomen. Note: The arrow shows the gastric mass.

as an EGD. The CT scans revealed a mild splenomegaly, while the other findings were normal. The endoscopy had no pathological findings.

\section{Discussion}

DLCL is a subtype of non-Hodgkin lymphomas. DLCLs represent a diverse spectrum of lymphoid neoplasms with variable clinical, histologic, immunophenotypic, cytogenetic, molecular, and genetic features, ${ }^{3}$ and they are of B-cell origin. According to the literature, B-cell-restricted markers (CD19,

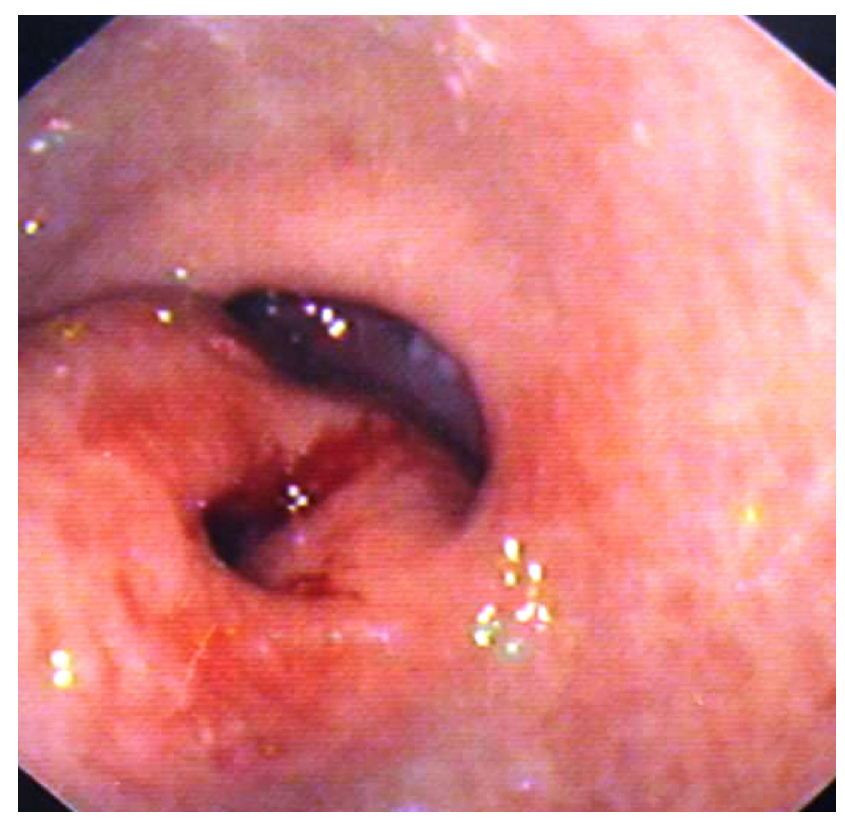

Figure 2 Esophagogastroduodenoscopy of the tumor in the gastric antrum. 


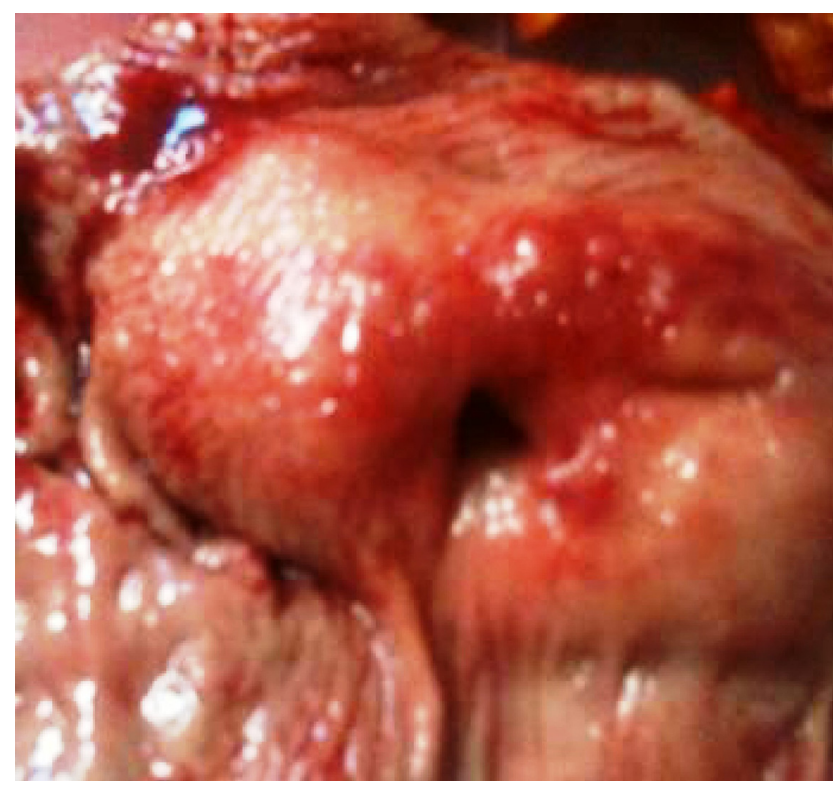

Figure 3 Gastrointestinal stromal tumor surgical specimen.

CD20, CD22) are expressed in the majority of DLCLs. The most common activation antigens are expressed through the HLA-DR system. In contrast to the markers mentioned above, CD23 is less frequently expressed $(0 \%-25 \%)$. The etiologic factor of these lymphomas is considered to be the mutations or allelic losses of the TP53 tumor suppressor gene (17p13.1). These changes are considered to be relevant with the evolution of these neoplasms. ${ }^{4,5}$ Another gene, the bcl-2 oncogene, is overexpressed in DLCLs. ${ }^{6-8}$ The bcl-2 is an important protein in the apoptotic pathway and is considered to have a critical role in drug resistance. The Bcl-2 protein is present in normal tissues, as well as in neoplastic ones, and high levels of this protein offer a survival advantage in B-cells by inhibiting apoptosis. ${ }^{6-8}$

Mediastinal B-cell lymphoma is a recently identified subtype of diffuse large B-cell lymphoma. ${ }^{9}, 10$ The pathogenesis of mediastinal B-cell lymphoma includes the activation of NF-KB pathways and the $J A K 2$ genes. ${ }^{11,12}$ The NF- $\kappa B$ signaling pathway controls the cell death regulatory genes, resulting in the control of B-cell survival. ${ }^{13,14}$ There is a simultaneous decrease in the JAK signaling pathway. ${ }^{15,16}$ The two pathways mentioned above are a result of the increased expression of IL-13. ${ }^{17}$ The signal transducer and activator of transcription-1, tumor necrosis factor, and tumor necrosis factor receptorassociated factor are increased. ${ }^{16}$ Additionally, there is a nuclear translocation of the c-REL protein ${ }^{13,18,19}$ (Figure 4). GISTs are mesenchymal tumors originating from the pluripotential mesenchymal stem cell, which is programmed to differentiate into the interstitial Cajal cell. ${ }^{2}$ GISTs are typically defined by the expression of c-KIT (CD117) and CD34 in the tumor cells. ${ }^{20}$ The $c-K I T$ oncogene is located in

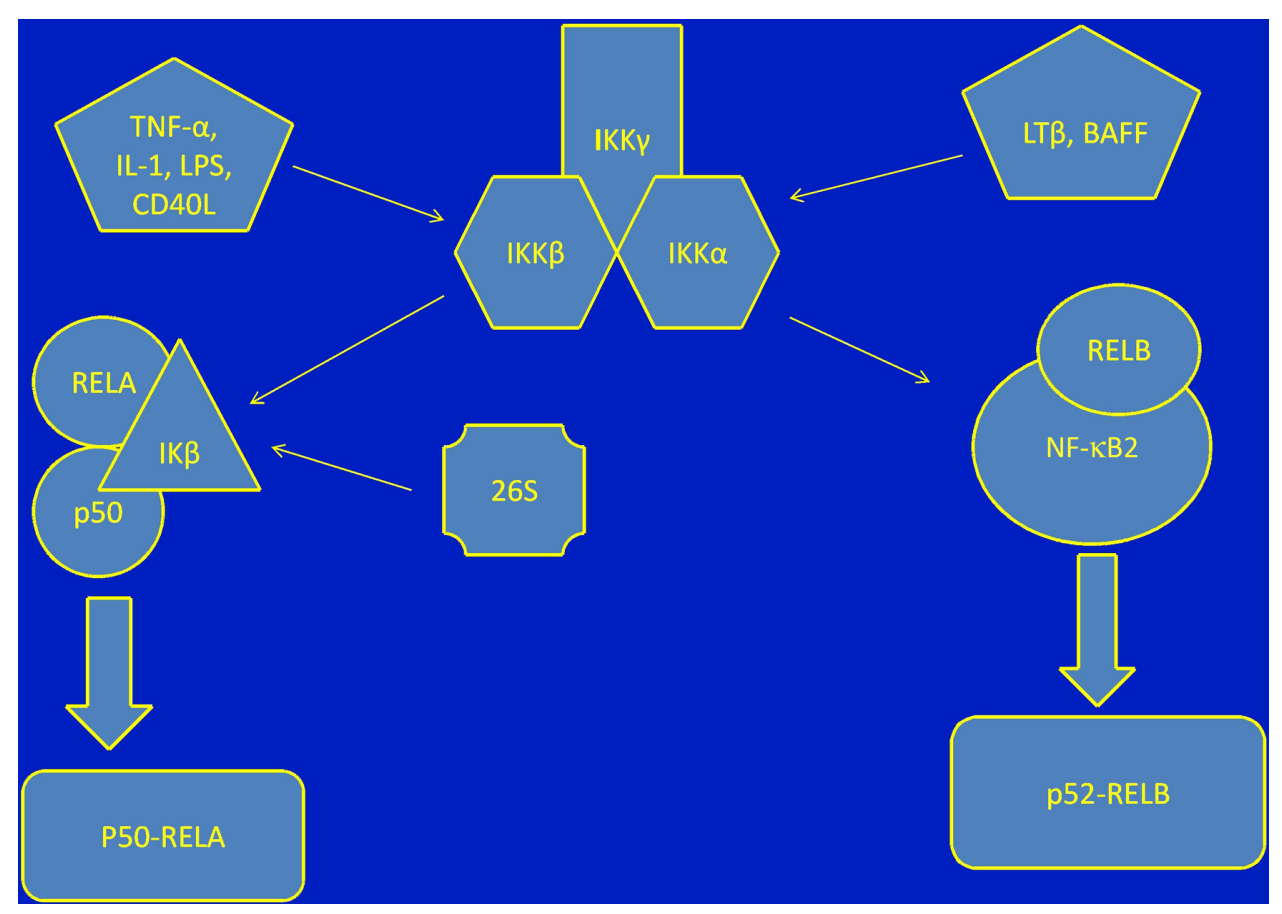

Figure $4 \mathrm{NF}-\kappa \mathrm{B}$ activation pathways.

Abbreviations: IK $\beta$, IK $\beta$ kinase; IKK $\gamma$, nuclear factor kappa-B kinase subunit gamma; TNF- $\alpha$, tumor necrosis factor- $\alpha$; RELA, transcription factor RelA; $26 \mathrm{~S}$, $26 \mathrm{~S}$ proteasome;

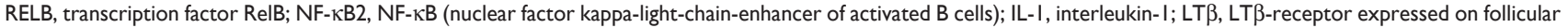
dendritic cells precursor; IKK $\alpha$, nuclear factor kappa-B kinase subunit gamma; IKK $\beta$, nuclear factor kappa-B kinase subunit gamma (IKK- $\beta$ ); CD40L, CD40 ligand. 
chromosome $4 .^{21}$ The expression of CD 117 is present in $85 \%$ $95 \%$ of GISTs. The remaining 3\%-5\% of c-KIT-negative GISTs is positive for PDGFR $\alpha$ mutations and PDGFR $\alpha$ mutations, and there is a small percentage of wild-type c-KIT mutations. $^{22,23}$ The mutations in oncogenic KIT genes are present in exons $9,11,13$, and $17 .{ }^{24,25}$ The mutations in exon 11 are most commonly deletions and substitutions, whereas duplications and insertions are less common. The locus of the mutation is codon 558 in $5^{\prime} \mathrm{KIT} .{ }^{26}$ As far as PDFGR $\alpha$ is concerned, there are mutations located in exons 12,14 , and 18. Both c-KIT and PDGRF $\alpha$ expression provoke a tyrosine kinase pathway in the cell. ${ }^{27}$ The activation of this signaling system results in uncontrolled phosphorylation and tissue growth. ${ }^{28}$ Because of the fact that $5 \%-15 \%$ of GISTs lack these mutations, scientists believe that there is an additional pathway that has not yet been discovered. ${ }^{28}$

GISTs are malignant neoplasms, and this fact makes the tumor prognostic factors extremely important. The most important prognostic factors are sizes greater than $5 \mathrm{~cm}$, mitotic activity (mitotic counts greater than one to five per ten high-powered fields), diffuse moderate atypia, and coagulation necrosis. ${ }^{29,30}$ The $c$-KIT oncogene was recently added to these mutation criteria (Table 1).

Although there have been impressive advances in targeted therapy, surgery resection with preservation of the pseudocapsule remains the primary mode of therapy for localized GISTs. ${ }^{31}$ Surgical resection can be laparoscopic or even endoscopic in cases of patients who cannot be treated with an open surgery. ${ }^{32,33}$ Surgery is used in three main situations: as an initial treatment (primary surgery) after diagnosis, especially in solitary tumors, which can be easily removed; after neoadjuvant treatment in order to reduce the

Table I Gastrointestinal stromal tumor staging system ${ }^{29}$

- Benign (no tumor-related mortality detected)

Group I (no larger than $2 \mathrm{~cm}$, no more than five mitoses/50 HPF)

- Probably benign (very low malignancy potential, $<3 \mathrm{PD}$ )

Group $2(2<\mathrm{t} \leq 5 \mathrm{~cm}$, no more than five mitoses/50 HPF)

Group 3a $(5<\mathrm{t} \leq 10 \mathrm{~cm}$, no more than five mitosis/50 HPF)

- Uncertain or low malignancy potential (no PDs but too few cases to reliably determine prognosis)

Group 4 (no larger than $2 \mathrm{~cm}$, more than five mitosis/50 HPF)

- Low to moderate malignancy potential (12\%-15\% tumor-related mortality)

Group 3b ( $>10 \mathrm{~cm}$, no more than five mitosis/50 HPF)

Group $5(2<\mathrm{t} \leq 5 \mathrm{~cm}$, more than five mitosis/50 HPF)

- High malignancy potential (49\%-86\% tumor-related mortality detected)

Group 6a ( $5<\mathrm{t} \leq 10 \mathrm{~cm}$, more than five mitosis/50 HPF)

Group $6 \mathrm{~b}(>10 \mathrm{~cm}$, more than five mitosis/50 HPF)

Abbreviations: HPF, high-pass filter; PD,progressive disease. size of the neoplasm; and, occasionally, for symptomatic relief in advanced metastatic disease, known as debulking surgery. ${ }^{31}$ It is considered very important that these tumors should be handled carefully in order to avoid tumor rupture and spread. Lymphadenectomy is not routinely recommended since GISTs rarely metastasize to the lymph nodes. Additionally, GISTs have poor response to conventional chemotherapy and radiation therapy. ${ }^{31,34}$

The last decade has seen significant progress in targeted therapy. Since Hirota et $\mathrm{al}^{20,35}$ discovered the role of c-KIT in GISTs, scientists have managed to find agents that block the molecular pathway of the oncogene proteins. In fact, scientists used imatinib and sunitinib maleate, the ATP binding agents of BCRABL, in the therapy of metastatic GISTs with very encouraging results. ${ }^{28,31,36,37}$ Those drugs bind and stabilize the inactivated form of the receptor tyrosine kinases, which leads to the inhibition of phosphorylation and downstream KIT-signaling activation. ${ }^{28,31,36}$ Imatinib binds to a specific amino acid residue within the ATP binding pocket and in the activation loop, ${ }^{31}$ whereas sunitinib interacts with different amino acids within the ATP binding pocket. ${ }^{31}$ Additionally, disease progression is considered to be a result of $c$-KIT mutations in exons 13,14 , and 17, which decrease the tumor sensitivity to imatinib and additional chemotherapy. ${ }^{28}$

Although there are reports of dispersants in the literature of patients with coexisting non-Hodgkin lymphoma and GISTs, there is nothing to the authors' knowledge indicating that there is a common molecular pathway between these two diseases.

\section{Conclusion}

Although there are references to dispersants in the literature about patients with both non-Hodgkin lymphoma and GISTs, there is no common molecular pathway between these two diseases. ${ }^{38}$ Genetic surveys have been done to try to establish a connection between lymphomas and GISTs, ${ }^{39}$ but there are no encouraging results. We believe that there should be further scientific interest on this field.

\section{Authors' contributions}

M Karanikas, N Machairiotis, P Zarogoulidis, and A Stylianaki wrote the manuscript. N Lyratzopoulos, A Mitrakas, and A Polychronidis performed the surgery. N Courcoutsakis evaluated the radiographic findings. M Spanoudakis treated the patient while he was a member of the Hematology Department, University General Hospital of Alexandroupolis, Democritus University of Thrace, Alexandroupolis, Greece. 
G Kouklakis, M Karanikas, N Lyratzopoulos, A Mitrakas, and A Polychronidis treated the patient.

\section{Disclosure}

The authors report no conflicts of interest in this work.

\section{References}

1. Evans LS, Hancock BW. Non-Hodgkin lymphoma. Lancet. 2003; 362(9378):139-146

2. Kindblom LG, Remotti HE, Aldenborg F, Meis-Kindblom JM. Gastrointestinal pacemaker cell tumor (GIPACT): gastrointestinal stromal tumors show phenotypic characteristics of the interstitial cells of Cajal. Am J Pathol. 1998;152(5):1259-1269.

3. Harris NL, Jaffe ES, Stein H, et al. A revised European-American classification of lymphoid neoplasms: a proposal from the International Lymphoma Study Group. Blood. 1994;84(5):1361-1392.

4. Mahadevan D, Fisher RI. Novel therapeutics for aggressive non-Hodgkin's lymphoma. J Clin Oncol. 2011;29(14):1876-1884.

5. Nakamura H, Said JW, Miller CW, Koeffler HP. Mutation and protein expression of p53 in acquired immunodeficiency syndrome-related lymphomas. Blood. 1993;82(3):920-926.

6. Gascoyne RD, Adomat SA, Krajewski S, et al. Prognostic significance of $\mathrm{Bcl}-2$ protein expression and $\mathrm{Bcl}-2$ gene rearrangement in diffuse aggressive non-Hodgkin's lymphoma. Blood. 1997;90(1):244-251.

7. Miyashita T, Reed JC. Bcl-2 oncoprotein blocks chemotherapy-induced apoptosis in a human leukemia cell line. Blood. 1993;81(1):151-157.

8. Pasqualucci L, Trifonov V, Fabbri G, et al. Analysis of the coding genome of diffuse large B-cell lymphoma. Nat Genet. 2011;43(9):830-837.

9. Lazzarino M, Orlandi E, Paulli M, et al. Primary mediastinal B-cell lymphoma with sclerosis: an aggressive tumor with distinctive clinical and pathologic features. J Clin Oncol. 1993;11(12):2306-2313.

10. Barth TF, Leithäuser F, Joos S, Bentz M, Moller P. Mediastinal (thymic) large B-cell lymphoma: where do we stand? Lancet Oncol. 2002;3(4):229-234.

11. Bentz M, Barth TF, Bruderlein S, et al. Gain of chromosome arm 9p is characteristic of primary mediastinal B-cell lymphoma (MBL): comprehensive molecular cytogenetic analysis and presentation of a novel MBL cell line. Genes Chromosomes Cancer. 2001;30(4):393-401.

12. van Besien K, Kelta M, Bahaguna P. Primary mediastinal B-cell lymphoma: a review of pathology and management. J Clin Oncol. 2001;19(6):1855-1864.

13. Karin M, Cao Y, Greten FR, Li ZW. NF-kappaB in cancer: from innocent bystander to major culprit. Nat Rev Cancer. 2002;2(4):301-310.

14. Feuerhake F, Kutok JL, Monti S, et al. NFkappaB activity, function, and target-gene signatures in primary mediastinal large B-cell lymphoma and diffuse large B-cell lymphoma subtypes. Blood. 2005;106(4): 1392-1399.

15. Steidl C, Gascoyne RD. The molecular pathogenesis of primary mediastinal large B-cell lymphoma. Blood. 2011;118(10):2659-2669.

16. Savage KJ, Monti S, Kutok JL, et al. The molecular signature of mediastinal large B-cell lymphoma differs from that of other diffuse large B-cell lymphomas and shares features with classical Hodgkin lymphoma. Blood. 2003;102(12):3871-3879.

17. Roy B, Bhattacharjee A, Xu B, Ford D, Maizel AL, Cathcart MK. IL-13 signal transduction in human monocytes: phosphorylation of receptor components, association with Jaks, and phosphorylation/ activation of stats. J Leukoc Biol. 2002;72(3):580-589.

18. Skarin AT, Dorfman DM. Non-Hodgkin's lymphomas: current classification and management. CA Cancer J Clin. 1997;47(6): 351-372.

19. Gutierrez-Garcia G, Cardesa-Salzmann T, Climent F, et al. Gene-expression profiling and not immunophenotypic algorithms predicts prognosis in patients with diffuse large B-cell lymphoma treated with immunochemotherapy. Blood. 2011;117(18):4836-4843.
20. Hirota S, Isozaki K, Moriyama $\mathrm{Y}$, et al. Gain-of-function mutations of c-kit in human gastrointestinal stromal tumors. Science. 1998;279(5350): 577-580.

21. Badalamenti G, Rodolico V, Fulfaro F, et al. Gastrointestinal stromal tumors (GISTs): focus on histopathological diagnosis and biomolecular features. Ann Oncol. 2007;18 Suppl 6:vi136-vi140.

22. Bai CG, Hou XW, Wang F, et al. Stem cell factor-mediated wild-type KIT receptor activation is critical for gastrointestinal stromal tumor cell growth. World J Gastroenterol. 2012;18(23):2929-2937.

23. Lamb G, Ambrale S, Lee B, Gupta R, Rafiyath SM, Liu D. Recent advances and novel agents for gastrointestinal stromal tumor (GIST). J Hematol Oncol. 2012;5(1):21.

24. Wong NA, Deans ZC, Ramsden SC. The UK NEQAS for Molecular Genetics scheme for gastrointestinal stromal tumour: findings and recommendations following four rounds of circulation. J Clin Pathol. 2012;65(9)786-790.

25. Suzuki K, Kaneko G, Kubota K, et al. Malignant tumor, of the gastrointestinal stromal tumor type, in the greater omentum. J Gastroenterol. 2003;38(10):985-988.

26. Lasota J, Kuban W, Wardelmann E, et al. KIT codon 558 insertions in gastrointestinal stromal tumors. Analysis of 17 rare KIT mutants. Hum Pathol. 2008;39(12):1728-1736.

27. Kang HJ, Koh KH, Yang E, et al. Differentially expressed proteins in gastrointestinal stromal tumors with KIT and PDGFRA mutations. Proteomics. 2006;6(4):1151-1157.

28. Gramza AW, Corless CL, Heinrich MC. Resistance to tyrosine kinase inhibitors in gastrointestinal stromal tumors. Clin Cancer Res. 2009;15(24):7510-7518.

29. Miettinen M, Sobin LH, Lasota J. Gastrointestinal stromal tumors of the stomach: a clinicopathologic, immunohistochemical, and molecular genetic study of 1765 cases with long-term follow-up. Am J Surg Pathol. 2005;29(1):52-68.

30. Sobin LH, Compton CC. TNM seventh edition: what's new, what's changed: communication from the International Union Against Cancer and the American Joint Committee on Cancer. Cancer. 2010; 116(22):5336-5339.

31. Tan CB, Zhi W, Shahzad G, Mustacchia P. Gastrointestinal stromal tumors: a review of case reports, diagnosis, treatment, and future directions. ISRN Gastroenterol. 2012;2012:595968.

32. Jeong IH, Kim JH, Lee SR, et al. Minimally invasive treatment of gastric gastrointestinal stromal tumors: laparoscopic and endoscopic approach. Surg Laparosc Endosc Percutan Tech. 2012;22(3):244-250.

33. Novitsky YW, Kercher KW, Sing RF, Heniford BT. Long-term outcomes of laparoscopic resection of gastric gastrointestinal stromal tumors. Ann Surg. 2006;243(6):738-745, discussion 745-737.

34. Pidhorecky I, Cheney RT, Kraybill WG, Gibbs JF. Gastrointestinal stromal tumors: current diagnosis, biologic behavior, and management. Ann Surg Oncol. 2000;7(9):705-712.

35. Hirota S, Ohashi A, Nishida T, et al. Gain-of-function mutations of platelet-derived growth factor receptor alpha gene in gastrointestinal stromal tumors. Gastroenterology. 2003;125(3):660-667.

36. Lai EC, Lau SH, Lau WY. Current management of gastrointestinal stromal tumors - a comprehensive review. Int J Surg. 2012;10(7): 334-340.

37. Wardelmann E, Losen I, Hans V, et al. Deletion of Trp-557 and Lys-558 in the juxtamembrane domain of the c-kit protooncogene is associated with metastatic behavior of gastrointestinal stromal tumors. Int J Cancer. 2003;106(6):887-895.

38. Herbers AH, Keuning JJ. Staging for CLL-type non-Hodgkin's lymphoma reveals a gastrointestinal stromal tumour. Neth $J$ Med. 2005;63(2):74-75.

39. Zimpfer A, Went P, Tzankov A, et al. Rare expression of KIT (CD117) in lymphomas: a tissue microarray study of 1166 cases. Histopathology. 2004;45(4):398-404. 


\section{Publish your work in this journal}

OncoTargets and Therapy is an international, peer-reviewed, open access journal focusing on the pathological basis of all cancers, potential targets for therapy and treatment protocols employed to improve the management of cancer patients. The journal also focuses on the impact of management programs and new therapeutic agents and protocols on

patient perspectives such as quality of life, adherence and satisfaction. The manuscript management system is completely online and includes a very quick and fair peer-review system, which is all easy to use. Visit http://www.dovepress.com/testimonials.php to read real quotes from published authors.

Submit your manuscript here: http://www.dovepress.com/oncotargets-and-therapy-journal 